\title{
Micronutrients and neurodevelopment: An update
}

\author{
Horacio F. González, M.D. ${ }^{a}$, and Silvana Visentin, Biochemist ${ }^{a}$
}

\begin{abstract}
Micronutrients make up the central nervous system structure and play major functional roles: they stimulate nerve cell development, migration, and differentiation.

The goal of this study is to review the scientific literature regarding the role of micronutrients in infant brain structure and function. Thus, we aim at providing pediatricians with knowledge on the importance of introducing all nutrients into the diet based on breast milk composition. The following databases were reviewed: MEDLINE, through PubMed, TRIP Database, and LILACS.

An adequate nutrient supply, including calcium, copper, choline, iron, folic acid, iodine, and vitamins during pregnancy and lactation and in complementary feeding will have an effect on brain development and/or function.

Key words: infant neurodevelopment, nutrition, breast milk, pregnancy, micronutrients.
\end{abstract}

http:/ /dx.doi.org/10.5546/aap.2016.eng.570

\section{INTRODUCTION}

The development of the central nervous system (CNS) is a genetically determined, dynamic process which is modulated by a set of epigenetic factors. ${ }^{1}$

An inadequate supply of some micronutrients may have a negative impact on brain structure or function.

a. Institute for

Development and Pediatric Research (Instituto de Desarrollo e Investigaciones Pediátricas, IDIP), Hospital de Niños de La Plata. Ministry of Health/Scientific Research Commission of the Province of Buenos Aires.

E-mail address:

Horacio F. González, M.D. horaciofgonzalez@gmail. com

Funding:

None.

Conflict of interest: None.

Received: 6-30-2016 Accepted: 7-5-2016 through PubMed, TRIP Database, and LILACS for publications made between 2000 and 2016.

\section{Choline}

The proliferation, differentiation and migration of neural stem cells take place during embryonic development. Choline is involved in this whole process. ${ }^{5}$ It is a component of the phospholipid, phosphatidylcholine, and sphingomyelin membranes, and a precursor of the acetylcholine neurotransmitter.

It is the main source of methyl groups, necessary for deoxyribonucleic acid (DNA) and histone methylation. Choline metabolism is closely related to folate, vitamins $\mathrm{B} 6$ and $\mathrm{B} 12$, and methionine, and an alteration in any of these metabolic pathways is associated with changes in the others. ${ }^{6}$

Choline is involved in methionine synthesis from homocysteine. Choline deficiency during gestation determines the development of spina bifida, both in experimental animals and in humans. Choline supply to pregnant women has the following effects on their offspring: increases cell proliferation, reduces hippocampal apoptosis, increases neuron size, and improves learning and visualspatial and auditory memory. The opposite occurs when there is choline deficiency. ${ }^{7.8}$

\section{Iron}

Iron-deficiency anemia (IDA) is a public health problem that affects pregnant women and infants younger than 2 years old; in both populations, the CNS is highly-vulnerable.

It has been demonstrated that infants with IDA have worse results in mental and psychomotor developmental outcomes than children without iron deficiency. It 
has been shown that children with moderate IDA in the first months of life which is corrected after they turn 5 years old continue having a poor neurodevelopmental outcome..$^{9,10}$

The occurrence of IDA during brain development of experimental animals has resulted in a permanent reduction of iron content in the brain. Iron is essential for myelination, and it has been demonstrated that iron deficiency causes hypomyelination, permanent deficiency in the number of dopamine receptors, and neurotransmission worsening. ${ }^{9,10}$ A slower transmission has been observed in the brainstem auditory pathway of children with IDA, which is associated with hypomyelination. ${ }^{11}$

Iron metabolism is closely related to docosahexaenoic acid (DHA) and has a major impact on neurodevelopment. ${ }^{12}$

Iron deficiency affects $\Delta$-6-desaturase activity, i.e., the synthesis of essential fatty acids. Iron is a cofactor of stearoyl-CoA desaturase, which acts as a catalyst for the conversion of palmitic acid (16:0) into palmitoleic acid (16:1n-7), and of stearic acid (18:0) into oleic acid (18:1n-9), and acts in the initial and subsequent stages of essential fatty acid synthesis elongation, such as the synthesis of $\alpha$-linolenic acid (18:3 n-3) into eicosapentaenoic acid (EPA) and DHA. ${ }^{13}$

Lactoferrin is a sialic acid-rich glycoprotein that carries human milk iron. It is associated with multiple benefits for health, including its ability to modulate immune function; but it is also very important because it facilitates milk iron absorption. Human milk contains significantly higher levels of lactoferrin than cow milk. According to a recent review of the role of lactoferrin, it seems to be an important nutrient for neurodevelopment, neuroprotection, and cognitive function during the rapid brain growth period. However, its mechanism of action has not been elucidated yet. There is also evidence of the specific benefits of lactoferrin, beyond the specific functions played by iron. ${ }^{14}$

\section{Iodine}

Iodine is an important micronutrient that is necessary for the production of thyroid hormone (TH). Severe iodine deficiency is one of the main preventable causes of mental retardation worldwide. ${ }^{15}$

The prevalence of severe iodine deficiency is very low thanks to iodized salt fortification. However, mild or moderate iodine deficiency is an alarming public health problem. ${ }^{16,17}$
Pregnant women are susceptible to iodine deficiency because their iodine requirements double during pregnancy. ${ }^{18}$ Maternal free T4 provides T3 to the fetal brain and is necessary for the thyroid hormone-dependent neurodevelopment. ${ }^{18}$ Thyroid hormone nuclear receptors are present in the fetal brain as of 8 or 9 weeks of gestation and attain adult levels by week $18 .{ }^{19}$ After week 9, neural proliferation and migration towards the cerebral cortex, the hippocampus, and the medial ganglionic eminence start. At the beginning of the second trimester, fetal hormones develop but iodine reserves are very low, so maternal hormones supplement the necessary levels until birth. A low iodine maternal diet reduces the level of free $\mathrm{T} 4$, causes fetal hypothyroxinemia, and brain damage, which may later worsen due to fetal hypothyroidism. The most serious consequence is cretinism, which is characterized by a profound mental retardation. ${ }^{17}$ There is unequivocal evidence of the brain damage caused by severe iodine deficiency during pregnancy. However, there is no accurate knowledge on the damage caused by mild or moderate iodine deficiency or the effect of late supplementation during pregnancy. Some authors have demonstrated that iodine deficiency affects non-verbal intelligence quotient and reading skills. ${ }^{15}$ Breastfeeding women who use iodized salt may transfer adequate amounts of iodine to their infants through breast milk. Weaning is a period of risk for iodine deficiency because iodine requirements are high during childhood. Experts recommend against the use of salt (regular or iodized) and cow milk (a major source of iodine) during the first year of life. The prevalence of iron deficiency in this period is high and affects iodine metabolism. $^{20}$

\section{Calcium}

The most important pathway for the influx of $\mathrm{Ca}^{++}$in excitable cells are voltagedependent calcium channels (VDCC). VDCC open and allow the selective flow of $\mathrm{Ca}^{++}$ions through the channels' pores; this results in a variety of intracellular processes, including neurotransmitter release, gene expression, modulation of membrane excitability, and neurite growth. $\mathrm{Ca}^{++}$channels are the main bond between the electrical signals of membrane surface and intracellular biochemical responses. ${ }^{21}$

$\mathrm{Ca}^{++}$is also involved, as a second messenger, in signal transduction, which controls neuron 
and glial cell production. Neuroblasts derived from the neuroepithelium are the first precursors of glial and neuronal populations and, following neural induction, they have to grow and proliferate to produce a large number of cells and thus form the nervous system. ${ }^{22}$ Neuroblasts express cell-surface receptors; in turn, these become activated by their ligand, induce intracellular $\mathrm{Ca}^{++}$mobilization, and stimulate cell proliferation..$^{23}$ The inhibition of these receptors by their antagonists prevents $\mathrm{Ca}^{++}$mobilization and neuroblast proliferation. ${ }^{24}$

\section{Zinc}

Zinc is a very important trace mineral for pre- and postnatal development. ${ }^{25}$ Its functions are related to gene expression, cell development and replication, and ribonucleic acid (RNA) and DNA synthesis, which are critical for cell growth, differentiation and metabolism. ${ }^{26}$ Zinc deficiency may affect cognitive development. ${ }^{27,28}$

Zinc plays a structural and regulatory role in several enzymes, through signal transduction, pre-secretory polymers, and gene transcription systems, which are essential for metabolism, growth, and human reproduction. Zinc is involved in the main metabolic pathways of macronutrients, nucleic acids, heme synthesis, connective tissue replacement, gene expression, tissue synthesis, and embryogenesis. Some research studies observed a correlation between maternal levels of zinc and motor and cognitive neurodevelopment during early childhood; others found that zinc supplementation in pregnant women did not have any effect on subsequent neurodevelopment. ${ }^{8}$

\section{COPPER}

Copper is involved in hemoglobin formation and is essential for bone, tendon, connective tissue, vascular system, and myelin development and maintenance. Myelin is formed by phospholipids, whose synthesis depends on the cytochrome $\mathrm{C}$ oxidase, a copper-dependent enzyme. A lack of copper in the body manifests as moderate to severe anemia, edemas, bone demineralization, growth failure, anorexia, and vulnerability to infections. Copper is involved in ferroxidase activity, and may serve as the basis for an accurate control of iron flow to the different tissues. ${ }^{29}$

Preterm infants and low birth weight infants are both populations vulnerable to copper deficiency. As is the case with iron and zinc, fetal hepatic copper accumulation occurs at the end of gestation to supply copper for the first months of life, a period with minimum intake of this nutrient. $^{30}$

\section{VITAMINS \\ Vitamin A}

Retinoids are involved in the signaling pathway that regulates gene expression. They control neuron differentiation and the pattern of neural tube development. Retinoids are implied in synaptic plasticity, learning, memory, and sleep. ${ }^{31}$ These are essential molecules for sight, normal embryonic development, and control of cell growth, differentiation, and death. ${ }^{32}$

Night blindness, anemia, and immunodeficiency are the main consequences of vitamin A deficiency. During pregnancy, it may cause teratogenic effects in body organs, such as the eyes, and the CNS. A manifestation of mild vitamin A deficiency is Bitot's spot. Severe vitamin A deficiency causes xerophthalmia, corneal ulcers, scarring and blindness. ${ }^{33}$ Excessive exposure may also cause teratogenic effects and malformations, such as spina bifida, hydrocephalus, cleft palate, anophthalmia, and limb deformity. ${ }^{34}$

Newborn infants' vitamin A deposits depend on breast milk to cover their needs and liver reserves. All mothers have reduced retinol levels in the first year postpartum, which progressively decreases vitamin A transfer from breast milk to the baby. ${ }^{35}$ This reinforces the concept that it is necessary to provide vitamin A supplementation during lactation. ${ }^{36}$

\section{Vitamin B1}

Thiamin (vitamin B1) is involved in carbohydrate synthesis and metabolism given that enzymes involved in this process require vitamin B to complete it. It also plays an important role in muscle contraction, nerve impulse conduction, and glucose absorption by the nervous system. ${ }^{37}$

The brain stem, the cerebellum and the brain's limbic system are highly sensitive to vitamin B1 deficiency (pseudohypoxia), and its pathophysiology is similar to a continuous oxygen deprivation. ${ }^{38}$

An incorrect vitamin B1 supplementation in soy-based formula showed that thiamin deficiency in infants causes encephalopathy, neuropathy, visual alterations, and death. Children who survive this type of deficiency have severe motor and cognitive sequelae and epilepsy. ${ }^{39-41}$ 


\section{Vitamin B6}

Vitamin B6 must be obtained from the diet because humans cannot synthesize it. The main bioactive form of vitamin B6 is pyridoxal-5 phosphate. It is an essential cofactor for the functioning of more than 140 enzymes required for amino acid synthesis, breakdown and interconversion. It is a cofactor that limits dopamine, serotonin, gamma-aminobutyric acid (GABA), and noradrenaline synthesis. The synthesis of all these neurotransmitters is very sensitive to vitamin B6 levels. In addition, it has a direct effect on immune function, and gene transcription and expression, and plays a significant role in brain glucose regulation. ${ }^{42-44}$

\section{Vitamin B9 (folic acid)}

Vitamin B9 plays an important role in cell division, and amino and nucleic acid synthesis and is, therefore, essential for growth. It is necessary for the normal development of the fetal spine, brain and skull, especially during the first four weeks of gestation. It is critical for the synthesis of DNA, which transfers the genetic make-up, and RNA, which is necessary for protein and body tissue formation and other cell processes. ${ }^{45}$

Folate coenzymes are necessary for the metabolism of important different amino acids, such as methionine synthesis from homocysteine. Folic acid deficiency is related to neural tube defects. ${ }^{46,47}$

It is necessary for tetrahydrobiopterin synthesis and regeneration, an essential cofactor for the enzymes that turn amino acids into neurotransmitters (serotonin, melatonin, dopamine, noradrenaline, adrenaline), and nitric oxide. $^{48}$

\section{Vitamin B12}

Like the rest of the vitamins in the vitamin B complex, vitamin B12 is important for CNS metabolism and maintenance. Together with folate, it plays a significant role in homocysteine metabolism. It is essential for the preservation of the myelin sheath around neurons and neurotransmitter synthesis. Vitamin B12 deficiency causes damage in the myelin sheath covering cranial, spinal and peripheral nerves. ${ }^{49}$ Vitamin B12 deficiency-related syndromes include myelopathy, neuropathy, neuropsychiatric disorders and, less frequently, optic nerve atrophy. Children with conditions related to hereditary cobalamin deficiency have
CNS damage characterized by a loss of white matter with delayed myelination. ${ }^{50}$

\section{Vitamin C}

Vitamin $C$ is an essential cofactor for numerous enzymatic reactions. Its functions include maintaining redox balance in the brain, modulating the cholinergic, catecholaminergic and glutaminergic systems, generally developing neurons through their maturation and differentiation, and forming myelin. In the developing brain, neuronal density and maturation are affected by vitamin $\mathrm{C}$ deficiency, which causes a reduced brain volume. ${ }^{51}$ Vitamin $\mathrm{C}$ deficiency also affects folic acid metabolism and iron absorption. ${ }^{52}$

\section{Vitamin D}

1,25-dihydroxycholecalciferol induces the nerve growth factor (NGF), promotes neurite growth, and inhibits neuronal apoptosis in the hippocampus. Vitamin D deficiency during the prenatal period is associated with alterations in some CNS structures because it reduces the expression of certain genes involved in brain and cerebellar growth.

The vitamin $\mathrm{D}$ receptor is expressed in glial cells and neurons, induces the NGF, is a potent inhibitor of mitosis and a potent promoter of cell differentiation. ${ }^{53}$

Vitamin D deficiency during neurodevelopment has been observed to cause behavioral, memory and learning disorders in adults. ${ }^{54}$

\section{Vitamin E}

$\alpha$-tocopherol is an antioxidant, maintains cell membrane integrity, and protects fat in lowdensity lipoproteins against oxidation. It is an essential compound for the adequate functioning and formation of the nervous system. It may cross membranes and enter into tissues, including the brain. Vitamin E deficiency is related to cerebellar ataxia, posterior cord medullary damage, and peripheral neuropathy. Ataxia due to isolated vitamin E deficiency is a familial, autosomal recessive disorder caused by a mutation in the gene that codes the $\alpha$-tocopherol transfer protein. ${ }^{55,56}$

\section{FINAL COMMENT}

An adequate diet in women of childbearing potential, and during pregnancy and lactation allows for an appropriate supply of the 
micronutrients necessary for neurodevelopment. It is critical to get all nutrients. A single nutrient cannot be believed to provide a benefit without the balanced supply of all the others. Knowing these mechanisms strengthens recommendations.

\section{REFERENCES}

1. Prado EL, Dewey KG. Nutrition and brain development in early life. Nutr Rev 2014;72(4):267-84.

2. González HF, Visentin S. Nutrientes y neurodesarrollo: lípidos. Actualización. Arch Argent Pediatr 2016;114(5):472-6.

3. Isaacs EB, Fischl BR, Quinn BT, Chong WK, et al. Impact of breast milk on intelligence quotient, brain size, and white matter development. Pediatr Res 2010;67(4):357-62.

4. Khedr EM, Farghaly WM, Amry Sel-D, Osman AA. Neural maturation of breastfed and formula-fed infants. Acta Paediatr 2004;93(6):734-8.

5. ZeiselSH.Nutrition in pregnancy: the argumentfor including a source of choline. Int J Womens Health 2013;5:193-9.

6. Zeisel SH. The supply of choline is important for fetal progenitor cells. Semin Cell Dev Biol 2011;22(6):624-8.

7. Zeisel SH. The fetal origins of memory: the role of dietary choline in optimal brain development. J Pediatr 2006;149(5 Suppl):S131-6.

8. Castro-Gago M,Novo-RodríguezMI,Gómez-LadoC,EirísPuñal J. Efecto neuroprotector de los factores dietéticos pre y perinatales sobre el neurodesarrollo. Rev Neurol 2007;44 (Supl 3):S1-S10.

9. Beard J. Recent evidence from human and animal studies regarding iron status and infant development. J Nutr 2007;137(2):524S-530S.

10. Beard JL, Connor JR. Iron status and neural functioning. Annu Rev Nutr 2003;23:41-58.

11. Monga M, Walia V, Gandhi A, Chandra J, et al. Effect of iron deficiency anemia on visual evoked potential of growing children. Brain Dev 2010;32(3):213-6.

12. RiouxFM,LindmarkG,HernellO. Doesinadequatematernal iron or DHA status have a negative impact on an infant's functional outcomes? Acta Paediatr 2006;95(2):137-44.

13. Baumgartner J, Smuts CM, Zimmermann MB. Providing male rats deficient in iron and n-3 fatty acids with iron and alpha-linolenic acid alone affects brain serotonin and cognition differently from combined provision. Lipids Health Dis 2014;13:97.

14. Wang B. Molecular determinants of milk lactoferrin as a bioactive compound in early neurodevelopment and cognition. J Pediatr 2016;173 Suppl:S29-36.

15. Ghassabian A, Steenweg-de Graaff J, Peeters RP, Ross HA, $\mathrm{t}$ al. Maternal urinary iodine concentration in pregnancy and children's cognition: results from a populationbased birth cohort in an iodine-sufficient area. BMJ Open 2014;4(6):e005520.

16. Pearce EN, Andersson M,Zimmermann MB. Global iodine nutrition: where do we stand in 2013? Thyroid 2013; 23(5):523-8.

17. Skeaff SA. Iodine deficiency in pregnancy: the effect on neurodevelopment in the child. Nutrients 2011;3(2):265-73.

18. ZhouSJ,Anderson AJ,GibsonRA,MakridesM.Effectofiodine supplementation in pregnancy on child development and other clinical outcomes: a systematic review of randomized controlled trials. Am J Clin Nutr 2013;98(5):1241-54.

19. Williams GR. Neurodevelopmental and neurophysiological actions of thyroid hormone. J Neuroendocrinol 2008;20(6): 784-94.

20. Zimmermann MB. Are weaning infants at risk of iodine deficiency even in countries with established iodized salt programs? Nestle Nutr Inst Workshop Ser 2012;70:137-46.

21. Medel Matus JS, Ramos Morales FR, Correa Basurto J, Cruz Sánchez JS, et al. Participación de los canales de calcio dependientes de voltaje en el desarrollo de la epilepsia. Acta Bioquim Clín Latinoam 2010;44(3):329-35.

22. Gotz M, Huttner WB. The cell biology of neurogenesis. Nat Rev Mol Cell Biol 2005;6(10):777-88.

23. Lipskaia L, Hulot JS, Lompré AM. Role of sarco/ endoplasmic reticulum calcium content and calcium ATPase activity in the control of cell growth and proliferation. Pflugers Arch 2009;457(3):673-85.

24. Lin JH, Takano T, Arcuino G, Wang X, et al. Purinergic signaling regulates neural progenitor cell expansion and neurogenesis. Dev Biol 2007;302(1):356-66.

25. Castillo-Durán C, Perales CG, Hertrampf ED, Marín VB, et al. Effect of zinc supplementation on development and growth of Chilean infants. J Pediatr 2001;138(2):229-35.

26. Sandstead HH, Frederickson CJ, Penlad JG. History of zinc as related to brain. J Nutr 2000;130(2S Suppl):496S-502S.

27. Jiménez R, Martínez M, Peñalver R. Efecto del zinc sobre el crecimiento y desarrollo del niño con bajo peso al nacer. Colomb Med 2007;38(Supl 1):6-13.

28. Colombo J, Zavaleta N, Kannass KN, Lazarte F, et al. Zinc supplementation sustained normative neurodevelopment in a randomized, controlled trial of Peruvian infants aged 6-18 months. J Nutr 2014;144(8):1298-305.

29. Vashchenko G, Mac Gillivray RT. Multi-copper oxidases and human iron metabolism. Nutrients 2013;5(7):2289-313.

30. Harvey LJ, McArdle HJ. Biomarkers of copper status: a brief update. Br J Nutr 2008;99(Suppl 3):S10-3.

31. Tafti M, Ghyselinck NB. Functional implication of the vitamin A signaling pathway in the brain. Arch Neurol 2007;64(12):1706-11.

32. Blomhoff R, BlomhoffHK. Overview of retinoid metabolism and function. J Neurobiol 2006;66(7):606-30.

33. Semba RD. Impact of vitamin A on immunity and infection in developing countries. In: Bendich A, Decklebaum RJ, eds. Preventive Nutrition: The Comprehensive Guide for Health Professionals. 2nd ed. Totowa: Humana Press; 2001.P.329-46.

34. Elmadfa I, Meyer AL. Vitamins for the first 1000 days: preparing for life. Int J Vitam Nutr Res 2012;82(5):342-7.

35. Fujita M, Shell-Duncan B, Ndemwa P, Brindle E, et al. Vitamin A dynamics in breastmilk and liver stores: a life history perspective. Am J Hum Biol 2011;23(5):664-73.

36. Souza G, Dolinsky M, Matos A, Chagas C, et al. Vitamin A concentration in human milk and its relationship with liver reserve formation and compliance with the recommended daily intake of vitamin A in pre-term and term infants in exclusive breastfeeding. Arch Gynecol Obstet 2015;291(2):319-25.

37. Frank LL. Thiamin in clinical practice. JPEN J Parenter Enteral Nutr 2015;39(5):503-20.

38. Lonsdale D. Sudden infant death syndrome and abnormal metabolism of thiamin. Med Hypotheses 2015;85(6):922-6.

38. Shamir R. Thiamine-deficient infant formula: what happened and what have we learned? Ann Nutr Metab 2012;60(3):185-7.

39. Mimouni-Bloch A, Goldberg-Stern H,Strausberg R, Brezner A, et al. Thiamine deficiency in infancy: long-term followup. Pediatr Neurol 2014;51(3):311-6.

40. Fattal-Valevski A, Azouri-Fattal I, Greenstein YJ, Guindy $\mathrm{M}$, et al. Delayed language development due to infantile thiamine deficiency. DevMed Child Neurol 2009;51(8):629-34.

41. Dakshinamurti S, Dakshinamurti K. Vitamin B6. En ZempleniJ,SuttieJW, GregoryJFIII,Stover PJ,eds. Handbook of Vitamins. 5th ed. Boca Raton: CRC Press; 2014.P.351-96.

42. Kennedy DO. B vitamins and the brain: mechanisms, dose and efficacy-a review. Nutrients 2016;8(2):68. 
43. Anitha M, Abraham PM, Paulose CS. Striatal dopamine receptors modulate the expression of insulin receptor, IGF-1 and GLUT-3 in diabetic rats: effect of pyridoxine treatment. Eur J Pharmacol 2012;696(1-3):54-61.

44. Morse NL. Benefits of Docosahexaenoic acid, folic acid, vitamin Dand iodine on foetal and infant brain development and function following maternal supplementation during pregnancy and lactation. Nutrients 2012;4(7):799-840.

45. Cordero AM, Crider KS, Rogers LM, Cannon MJ, et al. Optimal serum and red blood cell folate concentrations in women of reproductive age for prevention of neural tube defects: World Health Organization guidelines. MMWR Morb Mortal Wkly Rep 2015;64(15):421-3.

46. Eichholzer M, Tönz O, Zimmermannn R. Folic acid: a public-health challenge. Lancet 2006;367(9519):1352-61.

47. Stahl SM. L-methylfolate: a vitamin for your monoamines. J Clin Psychiatry 2008;69(9):1352-3.

48. Scalabrino G. The multi-faceted basis of vitamin B12 (cobalamin) neurotrophism in adult central nervous system: lessons learned from its deficiency. Prog Neurobiol 2009;88(3):203-20.

49. Briani C, Dalla Torre C, Citton V, Manara R, etal.Cobalamin deficiency: clinical picture and radiological findings. Nutrients 2013;5(11):4521-39.
50. Hansen SN, Tveden-Nyborg P, LykkesfeldtJ. Does vitamin $C$ deficiency affect cognitive development and function? Nutrients 2014;6(9):3818-46.

51. Garófalo Gómez N, Gómez García AM, Vargas Díaz J, Novoa López L. Repercusión de la nutrición en el neurodesarrollo y la salud neuropsiquiátrica de niños y adolescentes. Rev Cubana Pediatr 2009;81(2).

52. Brown J, Bianco JI, McGrath JJ, Eyles DW. 1,25-dihydroxyvitamin D3 induces nerve growth factor, promotes neurite outgrowth and inhibits mitosis in embryonic rat hippocampal neurons. Neurosci Lett 2003;343(2):139-43.

53. McGrath J,Eyles D, Mowry B, Yolken R, et al. Low maternal vitamin D as a risk factor for schizophrenia: a pilot study using banked sera. Schizophr Res 2003;63(1-2):73-8.

54. Jayaram S, Soman A, Tarvade S, Londhe V. Cerebellar ataxia due to isolated vitamin E deficiency. Indian J Med Sci 2005;59(1):20-3.

55. Bourre JM. Effects of nutrients (in food) on the structure and function of the nervous system: update on dietary requirements for brain. Part 1: micronutrients. JNutr Health Aging 2006;10(5):377-85. 